\title{
The development of technology for production of zeolites from fly-ash from Troitskaya power plant
}

\author{
V.A. Snegirev, V.M. Yurk ${ }^{*}$ \\ Chemical-technological institute, Ural Federal University, Mira str., 28, Ekaterinburg, Russia \\ * Corresponding author:v.yurk@yandex.ru \\ This short communication (letter) belongs to the MOSM2O20 Special Issue.
}

(C) 2021, The Authors. This article is published in open access form under the terms and conditions of the Creative Commons Attribution (CC BY) license (http://creativecommons.org/licenses/by/4.o/).

\begin{abstract}
The study examines the technology of processing fly ash from Troitskaya power plant for the production of zeolite. The paper presents the results of laboratory studies evaluating the suitability of fly ash from Troitskaya power plant for the production of zeolites and the development of the zeolite production process. Fly ash contains a small amount of heavy metals that can complicate processing, but contains a large amount of silicon oxide. The technology consists of high-temperature alkaline activation of fly ash and hydrochemical synthesis. The resulting powder has a specific surface area of $89.7 \mathrm{~m}^{2} / \mathrm{g}$, determined by the BET method, and an average pore diameter of $0.345 \mu \mathrm{m}$. The static exchange capacity was $220 \mathrm{mg} / \mathrm{g}$.
\end{abstract}

\author{
Keywords \\ fly ash \\ metals \\ zeolites \\ waste treatment \\ thermal power plant residues \\ Received: 03.11.2020 \\ Revised: 25.12.2020 \\ Accepted: 25.12.2020 \\ Available online: 16.04 .2021
}

\section{Introduction}

Thermal power plant residues are divided into the fly ash, collected on electrostatic air cleaner, and slag formed under the combuster. Due to physical and chemical properties (small powdery particles of spherical shape, often hollow), fly ash is widely used in the production zeolites. However, their use may be limited by the high content of toxic metals [1].

The chemical and mineral-phase components of the flyash depend on the composition of the mineral part of the fuel, its calorific value, the combustion mode, the method of their capture and removal, and the place of selection from dumps. But, despite this, in the composition of all ashes, the same set of mineral components is observed. The main components of fly ash are silicon oxides, aluminum, iron, calcium, potassium, sodium and titanium, the main content of which in all ash is $50-60 \% \mathrm{SiO}_{2}, 20-30 \%$ $\mathrm{Al}_{2} \mathrm{O}_{3}, 5-10 \% \mathrm{Fe}_{2} \mathrm{O}_{3}[2,3]$. Such composition makes the ash an attractive raw material for the production of sorption materials such as zeolites.

The issue of obtaining zeolites from ash is not new and has long been studied by various researchers. It is possible to obtain zeolites of $\mathrm{NaX}, \mathrm{NaY}, \mathrm{NaA}$, and phillipsite modifications from fly ash. One of the methods of zeolite synthesis is the separation of fly ash into components - silicon oxide and aluminum oxide - by multi-stage leaching of the ash and then their crystallization in alkaline solutions in autoclaves at high pressures [4].
The purpose of this work is to determine the possibility of using the ash of Troitskaya power station for the production of zeolites, taking into account the toxic effect of metals.

\section{Experimental}

Fly ash from Troitskaya state district power station is captured by eight electrostatic air cleaner and mixed. The granulometric composition was determined by the sieve method (State Standard 2093-82). The density determination was carried out by hydrostatic weighing (State Standard 2160-2015). The phase analysis was performed using an XRD-700o X-ray diffractometer (Shimadzu, Japan) in filtered copper radiation. The survey was carried out in the range of Bragg angles $2 \Theta=3-80^{\circ}$ at a speed of $0.5 \% \mathrm{~min}$., $\mathrm{U}=40 \mathrm{kV}, \mathrm{I}=30 \mathrm{~mA}$. A semi-quantitative assessment of the content of mineral phases in the sample was performed. Chemical analysis of ash was performed in "VUKHIN" Corp. (State Standard 10538-87). The metal concentration was determined by atomic absorption method (AAS) using a double beam atomic absorption spectrometer AA-700o (Shimadzu, Japan) (State Standard 32977-2014) and inductively coupled plasma mass spectrometry (ICP-MS).

Zeolite was obtained by hydrochemical method with preliminary high-temperature activation. A heated magnetic stirrer, Heidolph MR Hei-Standard, was used for desilting. High-temperature activation of fly ash was performed in a laboratory electric furnace SNOL 6,7/1300 at a 
temperature of $550{ }^{\circ} \mathrm{C}$. At all stages of the process, a sodium hydroxide (HC) reagent was used. Zeolite crystallization took place in a liquid thermostat LOIP LT-316b with an accuracy of maintaining the temperature of $\pm 0.1{ }^{\circ} \mathrm{C}$.

The total pore volume was measured by mercury porometry using a modernized pore meter PA-3mV at a pressure range of $0.1-200 \mathrm{GPA}$, which corresponded to pore radii from 6520 to $3.75 \mathrm{~nm}$. The morphology of the resulting product was studied by scanning electron microscopy using a JSM 6490 (Jeol, Japan) scanning electron microscope.

The static exchange capacity for $\mathrm{Ca}^{2+}$ ions, converted to $\mathrm{CaO}$, was determined by the following method: a solution containing a calcium salt was added to $1 \mathrm{~g}$ of the sorbent, mixed and kept for $24 \mathrm{~h}$. Next, $10 \mathrm{~cm}^{3}$ of the solution was selected over the sorbent, the content of calcium ions was determined by complexometric titration. The ion exchange capacity of the zeolite was calculated by $\mathrm{CaO}$.

\section{Results and Discussion}

The X-ray diffraction (XRD) pattern of Troitskaya ash is shown in Fig. 1. The main components of the ash are quartz, mullite and magnetite, typical for this type of raw material. The amorphous phase is about $37 \%$ (calculated with respect to the ratio of the halos of the 1st and 2nd orders to the total scattered density in the range of angles $\left.2 \Theta=15-60^{\circ}\right)$. The density of the ash is $1.85 \mathrm{~kg} / \mathrm{m}^{3}$. The results of the chemical analysis of the ash components are presented in Table 1.

The total content of silicon oxide in ash is $55.2 \%$, and of aluminum oxide $-26.8 \%$, based on which, the ash can be classified as high-silica. This also suggests that the main part of alumina is most likely represented in the composition of mullite, while the amorphous phase consists mainly of silica. The presence of any additional macroscopic inclusions and minerals in the composition of the studied ash was not found. The obtained results are in good agreement with the data of [5].

The initial fly ash contains a large amount of the crystalline phase represented by the minerals mullite and quartz. The optimal technology for producing zeolite from ash of this composition is high-temperature activation with solid alkali and subsequent hydrochemical synthesis [6-8].

The data shown in Table 2 provide an indication of the potential toxicity of fly ash and its processed products. In addition, metal ions can reduce the adsorption capacity of zeolites [9,10]. However, the content of any metal does not exceed the established standards [11].
The content of silicon oxide in the ash is significantly more than required to obtain alkaline sodium hydroaluminate, so it was decided to conduct a pre-procedure of fly ash. The fly ash was leached in a solution of sodium hydroxide under constant stirring and heated to $90{ }^{\circ} \mathrm{C}$ to isolate excess silicon oxide of an amorphous phase. Silica is dissolved in an alkaline solution. Process parameters such as the alkali concentration, the liquid-to-solid ratio, and the duration of desilicization varied to achieve the maximum value for removing excess $\mathrm{SiO}_{2}$. The results of the experiments are shown in Table 3.

The table shows that the main influence on the process is the amount of alkali, respectively: the more alkali, the higher the result. This is because the amorphous silica interacts better with concentrated solutions to form sodium silicate. The average maximum extraction value is $25 \%$, which corresponds to the dissolution of most of the amorphous phase.

Based on the research conducted, the optimal process conditions were: $\mathrm{NaOH}$ concentration - $5 \mathrm{~mol} / \mathrm{l}$, liquid-tosolid ratio -10 , process duration $-5 \mathrm{~h}$. The selected technological parameters allow achieving the maximum reproducible extraction of silica without additional time and material costs. The resulting filtrate was analyzed for aluminum content. It was found that, under the selected conditions, aluminum oxide practically does not pass into the solution, concentrating in the composition of the treated material.

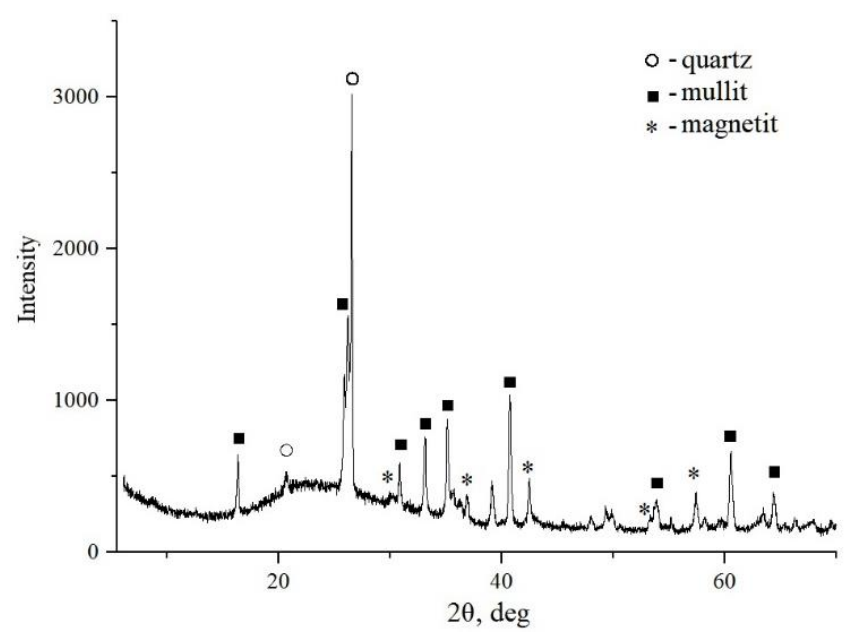

Fig. 1 XRD pattern of the initial Troitskaya ash

Table 1 Granulometric composition of fly ash from Troitskaya thermal power plant

\begin{tabular}{lllllll}
\hline Particle & $1-$ & $0.5^{-}$ & $0.25^{-}$ & $0.125^{-}$ & $0.063^{-}$ & 0.04 \\
size, $\mu \mathrm{m}$ & 0.5 & 0.25 & 0.125 & 0.063 & 0.04 & \\
\hline$\%$ & 2.0 & 13.4 & 30.6 & 34.8 & 12.2 & 7.0 \\
\hline
\end{tabular}

Table 2 Trace element content of fly ash from Troitskaya thermal power plant

\begin{tabular}{|c|c|c|c|c|c|c|c|c|}
\hline \multirow{2}{*}{ Method for determining the concentration } & \multicolumn{8}{|c|}{ Metal content, mass. $\%$} \\
\hline & $\mathrm{Be}$ & $\mathrm{Cr}$ & $\mathrm{Cu}$ & $\mathrm{Mn}$ & $\mathrm{Ni}$ & $\mathrm{Pb}$ & $\mathrm{V}$ & $\mathrm{Zn}$ \\
\hline AAS & - & 0.001 & 0.010 & 0.155 & 0.001 & 0.001 & 0.010 & 0.008 \\
\hline ICP-MS & - & 0.001 & 0.008 & 0.162 & 0.001 & 0.002 & 0.011 & 0.007 \\
\hline
\end{tabular}


Table 3 Results of the silicon removal experiment

\begin{tabular}{|c|c|c|c|c|}
\hline № & $\mathrm{NaOH}$ concentration, $\mathrm{mol} / \mathrm{l}$ & solid-to-liquid ratio & $\mathrm{t}, \mathrm{h}$ & removal, \% \\
\hline 1 & 2 & 8 & 3 & 16 \\
\hline 2 & 2.5 & 8 & 3 & 20 \\
\hline 3 & 3 & 6 & 4 & 16 \\
\hline 4 & 3 & 8 & 3 & 22 \\
\hline 5 & 4 & 8 & 4 & 24 \\
\hline 6 & 5 & 10 & 4 & 23 \\
\hline 7 & 5 & 10 & 5 & 26 \\
\hline 8 & 8 & 10 & 7 & 32 \\
\hline 9 & 8 & 8 & 3 & 26 \\
\hline 10 & 8 & 10 & 10 & 28 \\
\hline
\end{tabular}

The next stage of processing was opening the mineral phase of the ash and converting it into soluble compounds. We have chosen a method of temperature activation with alkali that does not require high pressure and ultrahigh temperatures, and is widely used by many researchers.

High-temperature activation of the fly ash was carried out by sintering with solid sodium hydroxide. The process took place at a temperature of up to $550{ }^{\circ} \mathrm{C}$ for $2 \mathrm{~h}$. The essence of this activation is the dissolution of quartz and mullite minerals with alkali, which under normal conditions does not occur as a result of this process, sodium silicate and aluminate are formed. The resulting sinter was then ground, dissolved in water, and the zeolite was crystallized. To confirm the need for pretreatment of ash, high-temperature activation was performed for both untreated and desilicized materials.

The ratio of reacting components required for the dissolution of the crystal phase and the production of zeolite was determined experimentally. Based on the data from [6-8], the first experiments selected a mass ratio of $\mathrm{NaOH} /$ ash from 1 to 2.5 . the result of sintering and subsequent repulpation of sinters obtained from both desilicated and untreated ash were powders containing a large amount of mullite and quartz, which indicates an insufficient amount of alkali for their dissolution. Zeolite was not found in these samples.

In subsequent experiments, the alkali content was increased. The required amount of $\mathrm{NaOH}$ was calculated from stoichiometric equivalent ratios required for mineral dissolution. The experiments were carried out at a $\mathrm{NaOH} /$ fly ash ratio equal to their stoichiometric amounts and with a one-and-a-half excess of hydroxide. Under the selected activation conditions, the specks of both types of ash had a uniform laurel-green color, without obvious signs of underburning of the fly ash. They were characterized by high strength, and therefore they had to be ground in a wet mortar.

As a result, after performing the repulpation and crystallization stages, zeolite powders with a pale beige color were obtained.

XRD patterns of zeolite powders obtained with a 1.5 excess of alkali from desilicated and untreated ash are shown in Fig. 2. The powders in both samples do not contain the original ash minerals. The zeolite composition in both cases can be characterized by the formula
$\mathrm{Na}_{1.84} \mathrm{Al}_{2} \mathrm{Si}_{2.88} \mathrm{O}_{9.68}$ (PDF 00-048-0731). Such composition is difficult to attribute to any particular type of zeolite; most likely, a mixture of them was obtained. The closest in composition are the zeolites $\mathrm{NaX}$ and NaY. The powder obtained from desilicized ash (Fig. 2b) has a higher crystallinity than the sample synthesized from raw materials (Fig. 2a), which also indicates a smaller amount of the amorphous phase in the powder composition. Increased crystallinity has a beneficial effect on the functional properties of the material. It can be concluded that the pretreatment of ash, namely the desilicization stage, is a necessary stage in the process of processing ash into zeolite from the ash of the Troitskaya power plant.

Fig. 3 shows the morphology of zeolite powder particles obtained by high-temperature activation of desilicized fly ash in the presence of 1.5 excess of alkali. The average
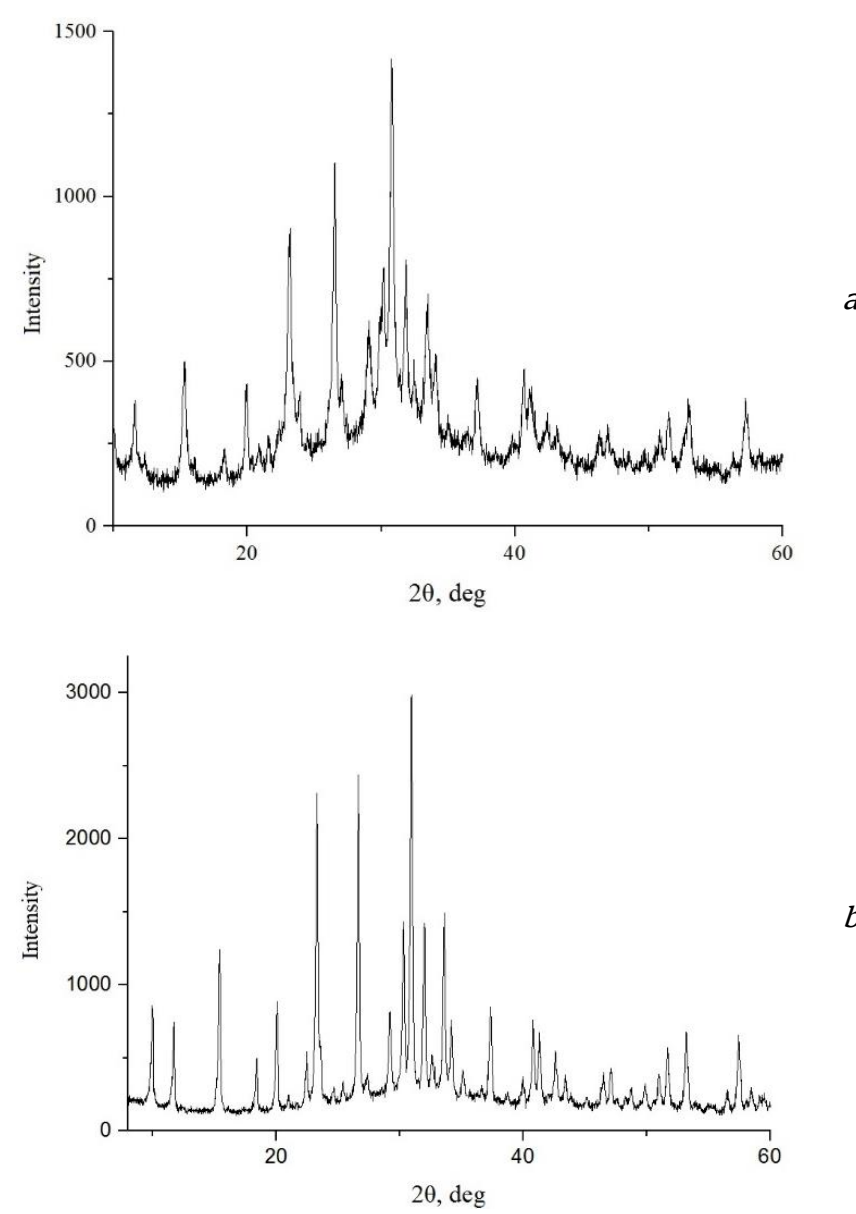

Fig. 2 XRD patterns of the zeolite obtained from: $a$ - non desilicated ash, $b$-desilicated ash 

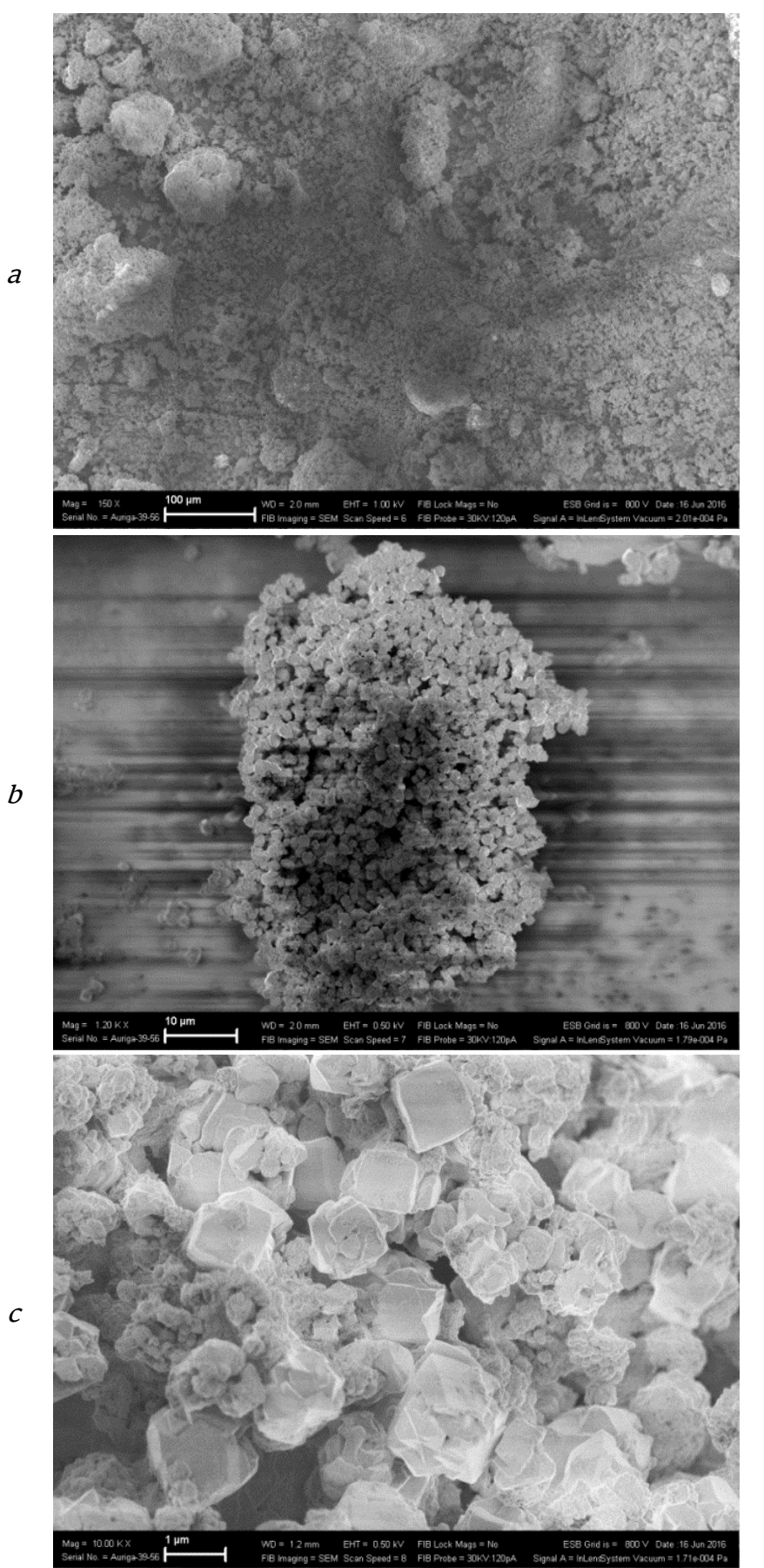

Fig. 3 SEM images of the obtained zeolite

size of the powder particles is about $70 \mu \mathrm{m}$ in length and $40 \mu \mathrm{m}$ in width (Fig. 3b). The powder also contains particles with smaller sizes, up to $10 \mu \mathrm{m}$ in length (Fig. 3a). Fig. 3c shows the surface morphology of one of these particles. They are cubic microcrystallites of zeolite surrounded by a structureless mass of the amorphous phase. Zeolite crystallizes in a cubic phase, with a rib length of about $1 \mu \mathrm{m}$.

The specific surface of obtained zeolite, determined by the BET method, is $89.7 \mathrm{~m}^{2} / \mathrm{g}$. For comparison, the values of this parameter for zeolites synthesized from fly ash in other researchers range from $62.01 \mathrm{~m}^{2} / \mathrm{g}$ [12] to $213.2 \mathrm{~m}^{2} / \mathrm{g}$ [13]. As shown by the results of mercury porometry, the surface of zeolite particles is characterized by the presence of a large number of micropores. The volume fraction of pores with a diameter from 0.1 to $5 \mu \mathrm{m}$ is $84.89 \%$. The total pore volume of the sample was $17.67 \mathrm{~cm}^{3} / \mathrm{g}$, and their average diameter was $0.345 \mu \mathrm{m}$.

Synthesized from fly ash zeolites are used in the purification of water from metal ions. The main parameter that characterizes the material for adsorption purposes is the ion exchange capacity. The ion exchange capacity of zeolite for the sorption of $\mathrm{Ca}^{2+}$ ions in terms of $\mathrm{CaO}$ was $220 \mathrm{mg} / \mathrm{g}$. The obtained value shows the applicability of the synthesized zeolite for sorption of heavy metal ions from an aqueous medium.

The synthesized zeolite is not soluble in dilute solutions of hydrochloric and sulfuric acids, as well as in concentrated sulfuric acid. It is half dissolved in concentrated hydrochloric acid.

As a result of the research, a technology for processing fly ash from Troitskaya GRES into zeolite was developed. The processing technology consists of operations for extracting excess silicon from ash, high-temperature activation, and hydrochemical crystallization, which require the use of available reagents and easy-to-use equipment.

Prospective technology for processing fly ash from Troitskaya power plant into zeolite consists of operations for extracting excess silicon from ash, high-temperature activation, and hydrochemical crystallization, which require the use of available reagents and easy-to-use equipment.

By its structure, the resulting zeolite can be attributed to a mixture of zeolites of the NaA and NaX types. The zeolite also has good ion exchange properties, typical of this material, which makes it attractive for use as a sorbent for wastewater treatment (removal of metal ions).

\section{References}

1. Bukhari SS, Jamshid Behin J, Kazemian H, Rohani S. Conversion of coal fly ash to zeolite utilizing microwave and ultrasound energies: A review. Fuel. 2015;140:250-66. doi:10.1016/j.fuel.2014.09.077

2. Ilica M, Cheeseman C, Sollars C, Knight J. Mineralogy and microstructure of sintered lignite coal fly ash. Fuel. 2003;82:331-6. doi:10.1016/So016-2361(02)00272-7

3. Adeeva LN, Borbat VF. Zola TETs - perspektivnoe syr'yo dlya promyshlennosti [Thermal power plant fly ash is a promising raw material for industry]. Vestnik Omskogo universiteta [Bulletin of the Omsk University]. 2009;2:137-47. Russian.

4. Myltykbaeva LA. Tekhnologiya polucheniya tseolitov iz zol TETs [Zeolites obtaining technology from thermal power stations ashes]. Energotekhnologii i resursosberezhenie [Energy technology and resource economy]. 2009:6:49-52. Russian.

5. Tumashov VF, Chernyavskiy IYa, Shapkin EN, inventors; "Ural'skiy nauchno-issledovatel'skiy i proektnyy institut stroitelnykh materialov", assignee. Sposob polucheniya mikrosfer iz vodnoy suspenzii letuchey zoly TETs [Method of production of microspheres from the aqueous suspension of thermal power plant fly ash]. Russian Federation patent RU 2017696. 15 Aug 1994. Russian.

6. Rios RCA., Williams CD, Roberts CL. A comparative study of two methods for the synthesis of fly ash-based sodium and potassium type zeolites. Fuel. 2009;88:1403-16. doi:10.1016/j.fuel.2009.02.012 
7. Kazemian H, Naghdali Z, Ghaffari Kashani T, Farhadi F. Conversion of high silicon fly ash to Na-P1 zeolite: Alkaline fusion followed by hydrothermal crystallization. Advanced Powder Technolologies. 2010;21:279-83. doi:10.1016/j.apt.2009.12.005

8. Molina A, Poole C. A comparative study using two methods to produce zeolites from fly ash. Minerals Engineering. 2004;17:167-73. doi:10.1016/j.mineng.2003.10.025

9. Jha VK, Nagae M, Matsuda M, Miyake M. Zeolite formation from coal fly ash and heavy metal ion removal characteristics of thus-obtained Zeolite $\mathrm{X}$ in multi-metal systems. J Environ Management. 2009;90(8):2507-14. doi:10.1016/j.jenvman.2009.01.009

10. Nascimento M, Soares PSM, de Souza VP. Adsorption of heavy metal cations using coal fly ash modified by hydrothermal method. Fuel. 2009;88:1714-9. doi:10.1016/j.fuel.2009.01.007
11. Tsennie i toksichnie elementy $\mathrm{v}$ tovarnyh uglyach Rossii: Spravochnik [Valuable and toxic elements in commercial coals in Russia: Directory]. Russian state company "Rosugol'". Moscow: Nedra; 1996. 235 p. Russian.

12. Grela A, Hebda M, Lach M, Mikula J. Thermal behavior and physical characteristics of synthetic zeolite from CFB-coal fly ash. Microporous and Mesoporous Materials. 2015;220:15562. doi:10.1016/j.micromeso.2015.08.036

13. Wang J, Li D, Ju F, Han L, Chang L, Bao W. Supercritical hydrothermal synthesis of zeolites from coal fly ash for mercury removal from coal derived gas. Fuel Processing Technology. 2015;136:96-105. doi:10.1016/j.fuproc.2014.10.020 